\title{
Antioxidant activity of synthetic diarylamines: A mitochondrial and cellular approach
}

\author{
Diana Pinto-Basto $^{\mathrm{a}, \mathrm{c}}$, João P. Silva ${ }^{\mathrm{a}}$, Maria-João R.P. Queiroz ${ }^{\mathrm{b}}$, António J. Moreno ${ }^{\mathrm{c}}$, Olga P. Coutinho ${ }^{\mathrm{a}, *}$ \\ a Department of Biology, University of Minho, Campus de Gualtar, 4710-057 Braga, Portugal \\ ${ }^{\mathrm{b}}$ Department of Chemistry, University of Minho, Campus de Gualtar, 4710-057 Braga, Portugal \\ ${ }^{\mathrm{c}}$ Department of Zoology, University of Coimbra, 3004-504 Coimbra, Portugal
}

\section{A R T I C L E I N F O}

\section{Article history:}

Received 26 May 2008

Received in revised form 23 September

2008

Accepted 7 October 2008

Available online 14 October 2008

\section{Keywords:}

Diarylamines

Antioxidants

Oxidative stress

Mitochondria

\begin{abstract}
A B S T R A C T
We investigated the antioxidant properties of two synthetic diarylamines, MJQ1 and MJQ2. For one of them (MJQ1) the synthesis procedure is herein described. The compounds showed maximal protection of $\mathrm{ADP} / \mathrm{Fe}^{2+}$ induced mitochondrial lipid peroxidation for $50 \mathrm{nM}(\mathrm{MJQ} 1)$ and $60 \mu \mathrm{M}(\mathrm{MJQ2})$ concentrations. Both compounds were also effective in the prevention of mitochondrial $\Delta \Psi$ collapse. The effective antioxidant dose of MJQ1 in mitochondria ( $50 \mathrm{nM}$ ) also proved to protect lipid peroxidation in PC12 cells and the effect seems not to be related with the compound's iron chelating ability. The modified structure of MJQ1 clearly resulted in an improvement of its antioxidant and toxic profile, evaluated in mitochondria and whole cells. This study demonstrates a high potential of these diarylamines, as radical scavengers, whose chemical structures can be manipulated if a specific target is well characterized.
\end{abstract}

(C) 2008 Elsevier B.V. and Mitochondria Research Society. All rights reserved.

\section{Introduction}

Substantial evidence supports the active involvement of free radicals in the development of several pathological conditions including neurodegenerative and cardiovascular diseases, diabetes, cancer or even normal aging (Lovell et al., 1995; Behl, 1999; Schroeter et al., 2000; Jang and Surh, 2001; Valko et al., 2006). Mitochondria are involved in several processes essential for cell survival, including energy production, redox control, calcium homeostasis, and in some biosynthetic and metabolic pathways. However, it has been recognized as the major source of ROS (reactive oxygen species, which include $\mathrm{O}_{2} \cdot{ }^{-},{ }^{\circ} \mathrm{OH}, \mathrm{H}_{2} \mathrm{O}_{2}$ ) within the cell, being an important target for oxidative damage. Mitochondrial or cytoplasmic ROS are able to attack the cellular components, including membrane lipids, proteins, and nucleic acids, leading to cell damage and/ or dysfunction and ultimately to cell death. Although the organisms have machinery of cellular defence, against oxidative stress, in some pathological conditions they are not enough to remove the excess of intracellular ROS (Bouchier-Hayes et al., 2005; Jezek and Hlavata, 2005). In the literature we can find abundant data about the antioxidant activity of several natural compounds like phenolic compounds, widely distributed in fruits and vegetables or in

Abbreviations: MJQ1, 6-(4-methoxyaniline)-2,3,7-trimethylbenzo[b]thiophene; MJQ2, ethyl 3-(3-aminopyridine)benzo[b]thiophene-2-carboxylate.

* Corresponding author. Tel.: +351 253604310; fax: +351 253678980 .

E-mail address: olgapc@bio.uminho.pt (O.P. Coutinho). plant-derived beverages such as tea and red wine (Schinella et al., 2002; Pardo et al., 2005; Gulcin et al., 2006). However, their use as active principles of drugs is very controversial. For that purpose, compounds obtained by organic synthesis have many advantages relatively to the natural ones: (1) their structures, precisely defined, can be manipulated in order to improve their activity and direct them to a specific target; (2) after establishment of the synthesis procedure, they can be produced in a large scale and (3) they can be obtained with a high degree of purity (Silva et al., 2006).

The secondary amines, particularly diarylamines obtained by organic synthesis, were described as important molecules due to their capacity as antioxidants, especially as radical scavengers (Scott, 1988). However, a precise mechanism for their action has not yet been clarified.

Information in the literature allowed some generalizations about the relationship between the antioxidant activity and the molecular structure of a compound. For instance, the presence of donor groups in an aromatic ring was shown to enhance the antioxidant activity, whereas groups that attract electrons, decrease that activity (Scott, 1988).

The redox properties of some diarylamines, derived from dehydroabietic acid, were evaluated by cyclic voltammetry and their free radical scavenging activity by the reduction of diphenyl-1-picrylhydrazyl (DPPH) radical (Esteves et al., 2001). The authors observed that the compounds that showed highest radical scavenging activity and the lowest oxidation potential have a p-methoxyphenyl moiety. In another study, the antioxidant 
properties of substituted diarylamines, in the benzo[b]thiophene series, were evaluated. High antioxidant activity was found for some of them, even better than those obtained for the classical antioxidants, like the butylated hydroxyanisole (BHA) or butylated hydroxytoluene (BHT), in terms of reducing power and radical scavenging activity (Ferreira et al., 2006). These last results may be indicative of a potential antioxidant capacity of diarylamines in benzo[b]thiophene series, which we are now evaluating in biological models.

So, the aim of this study is to examine the potential antioxidant properties of two new synthetic diarylamines (MJQ1 and MJQ2). Both have a benzo[b]thiophene nucleus, but also some structural differences, as can be seen in Fig. 1. The compound MJQ2 was synthesized in 2004 (Queiroz et al., 2004) and biological activity against Bacillus cereus and Candida albicans was shown, although the mechanism behind this activity was not investigated at the time. The compound MJQ1 is a related compound (synthesis procedure described herein) with a $p$-methoxyaniline group on the benzene ring, whereas MJQ2 has an aminopyridine group and an ester group on the thiophene ring. The relationship between these structural differences and their antioxidant capacity are now being evaluated.

The biological approaches used to assess the antioxidant potential of these new molecules involved studies at the mitochondrial level and studies with whole cells, namely the PC12 cell line. We analysed the antioxidant capacity of these diarylamines on isolated rat liver mitochondria subjected to oxidative stress, by the oxidant pair ADP and iron, as well as their effect on mitochondrial bioenergetics. As a complement of these studies in mitochondria, we evaluated the compounds effect on whole cells. The neuronal model of PC12 was used to assess the effect of these diarylamines on ascorbate/iron-induced lipid peroxidation, usually associated with neurodegenerative diseases (Pereira et al., 1999; Benedi et al., 2004; Silva et al., 2006). Furthermore, we determined the diarylamines' radical scavenging ability and metal ions chelating capacity $\left(\mathrm{Fe}^{3+}\right.$ in particular), in order to better understand their mechanism of action.

With this study we intend to provide useful data about cellular targets for these new compounds, electing them by this way, as good active principles to proceed further steps on the development process of drugs, with pharmacological potential.

\section{Materials and methods}

\subsection{Chemicals and reagents}

Tetraphenylphosphonium $\left(\mathrm{TPP}^{+}\right)$, sucrose and DOC were obtained from Merck (Darmstadt, Germany). Trolox was obtained from Sigma-Aldrich Chemie (Berlin, Germany). Fetal bovine serum (FBS) was obtained from Biochrom KG (Berlin, Germany) and horse serum was obtained from Gibco (Paisley, UK). All other reagents were obtained from Sigma Chemical Company (St. Louis, EUA). All solutions were prepared in Mili Q water.

Compounds in study, 6-(4-methoxyaniline)-2,3,7-trimethylbenzo[b]thiophene (MJQ1) and ethyl 3-(3-aminopyridine)benzo[b]thiophene-2-carboxylate (MJQ2) were synthesized in the Department of Chemistry of the University of Minho (Braga,
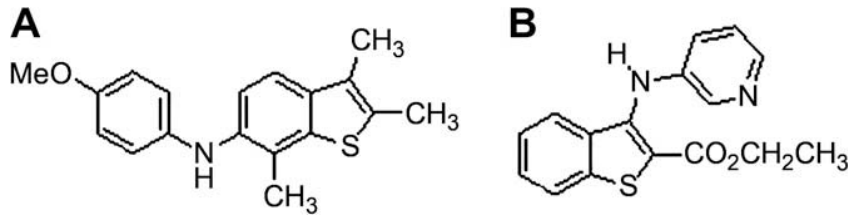

Fig. 1. Chemical structures of the diarylamines studied: MJQ1 (A) and MJQ2 (B).
Portugal). The synthesis and characterization of compound MJQ2 was published in 2004 (Queiroz M-JRP et al., 2004) and the synthesis of the MJQ1 compound follows below. Both diarylamines were reconstituted in DMSO and maintained at $-20^{\circ} \mathrm{C}$, protected from light.

\subsection{Synthesis of MJQ1}

The compound MJQ1 was synthesized using a palladium-catalyzed $\mathrm{C}-\mathrm{N}$ coupling. Column chromatography was performed on Macherey-Nagel silica gel 230-400 mesh. "Petroleum ether" refers to the fraction with boiling range $40-60{ }^{\circ} \mathrm{C}$. "Ether" refers to diethylether. rac.BINAP refers to the racemic mixture of 2,2'-bis-(diphenylphosphane) $1,1^{\prime}$-binapthyl. The ${ }^{1} \mathrm{H}$ NMR spectra was measured on a Varian Unity Plus at $300 \mathrm{MHz}$. The ${ }^{13} \mathrm{C}$ NMR spectra were measured in the same instrument at $75.4 \mathrm{MHz}$ (using DEPT $\theta 45^{\circ}$ ). Elemental analysis was determined on a LECO CHNS 932 elemental analyser.

In a dry Schlenk tube, it was added under Ar, toluene ( $5 \mathrm{ml}), 6$ bromo-2,3,7-benzo[b]thiophene (500 mg, 1,96 mmol), $\mathrm{Pd}(\mathrm{OAc})_{2}$ $(13.2 \mathrm{mg}, \quad 0.0588 \mathrm{mmol})$, rac.BINAP $(48.7 \mathrm{mg}, 0.0784 \mathrm{mmol})$, $\mathrm{Cs}_{2} \mathrm{CO}_{3} \quad(894 \mathrm{mg}, \quad 2.74 \mathrm{mmol}), \quad p$-methoxyaniline $(254 \mathrm{mg}$, $2.06 \mathrm{mmol}$ ). The mixture was heated at $100^{\circ} \mathrm{C}$ for $22 \mathrm{~h}$. After cooling, ether was added and the filtrate was evaporated under reduced pressure to give an oil, which was submitted to column chromatography using solvent gradient from neat petroleum ether to $20 \%$ ether/petroleum ether. The compound was obtained as a white solid which was crystallized from ether/petroleum ether to give colourless crystals (353 mg, 61\%), m.p. $137-138{ }^{\circ} \mathrm{C} .{ }^{1} \mathrm{H}$ NMR $\left(\mathrm{CDCl}_{3}\right) \delta 2.27\left(3 \mathrm{H}, \mathrm{s}, \mathrm{CH}_{3}\right), 2.40\left(3 \mathrm{H}, \mathrm{s}, \mathrm{CH}_{3}\right), 2.48\left(3 \mathrm{H}, \mathrm{s}, \mathrm{CH}_{3}\right)$, $3.80(3 \mathrm{H}, \mathrm{s}, \mathrm{OMe}), 5.28(1 \mathrm{H}$, broad $\mathrm{s}, \mathrm{NH}), 6.85(4 \mathrm{H}$, coalesced $\mathrm{ABq}, 2$, $6-\mathrm{H}$ and 3 , 5-H), $7.15(1 \mathrm{H}, \mathrm{d} J=8.4 \mathrm{~Hz}, 5-\mathrm{H}), 7.35(1 \mathrm{H}, \mathrm{d}$ $J=8.4 \mathrm{~Hz}, 4-\mathrm{H}) \mathrm{ppm} .{ }^{13} \mathrm{C} \mathrm{NMR}\left(\mathrm{CDCl}_{3}\right) \delta 11.41\left(\mathrm{CH}_{3}\right), 13.73\left(\mathrm{CH}_{3}\right)$, $15.80\left(\mathrm{CH}_{3}\right), 55.65\left(\mathrm{OCH}_{3}\right), 114.69(2 \times \mathrm{CH}), 117.67(\mathrm{CH}), 119.13$ (CH and $2 \times \mathrm{CH}$ ), 121.38 (C), 127.59 (C), 131.31 (C), 136.06 (C), 137.96 (C), 138.66 (C), 139.97 (C), 154.01 (C) ppm. Elemental analysis: $\mathrm{C}_{18} \mathrm{H}_{19} \mathrm{NOS}(297.415)$ requires: $\mathrm{C}, 72.69 ; \mathrm{H}, 6.44 ; \mathrm{N}, 4.71 ; \mathrm{S}$ $10.78 \%$. Found: C, $72.71 ; \mathrm{H}, 6.42 ; \mathrm{N}, 4.81 ; \mathrm{S}, 10.76 \%$.

\subsection{Animals}

The mitochondrial suspensions used in this work were isolated from Wistar strain rats (males and females) overnight-fasted, with 2.5-3 months and 200-300 g of body weight. The rats were kept under controlled light ( $12 \mathrm{~h}$ day/night cycle), temperature (22$24{ }^{\circ} \mathrm{C}$ ), humidity $(50-60 \%)$ conditions, and free access to water (pH 5.5) and food. The experiments were carried out in accordance with National Requirements for Vertebrate Animal Research and with the European Convention for the protection of animals used for experimental and other scientific purposes.

\subsection{Isolation of rat liver mitochondria}

Rat liver mitochondrial fractions were isolated by differential centrifugation according to the method previously described by Abreu et al., 2000. The final pellet was resuspended in $3-4 \mathrm{ml}$ of washing medium at a protein concentration of 30-40 protein $/ \mathrm{ml}$, evaluated by the biuret method (Gornall et al., 1949), using bovine serum albumin (BSA) as standard. All experiments were carried out within a $5 \mathrm{~h}$ period, after isolation of mitochondrial fractions.

\subsection{Oxygen consumption measurements}

Oxygen consumption was monitored using a Clark-type oxygen electrode (Yellow Springs Instruments, OH, USA) connected to a recorder (Kipp\&Zonen, BD 112), in a thermostated water-jacketed 
sealed glass chamber, with constant magnetic stirring, at $30^{\circ} \mathrm{C}$. The mitochondrial suspension $(1.5 \mathrm{mg}$ ) was incubated in $1 \mathrm{ml}$ of the reaction medium containing $125 \mathrm{mM}$ sucrose, $65 \mathrm{mM} \mathrm{KCl}$, $2.5 \mathrm{mM} \mathrm{MgCl}_{2}, 5 \mathrm{mM} \mathrm{KH} \mathrm{PO}_{4}$ and $10 \mathrm{mM}$ HEPES (pH 7.2). The reactions were initiated by adding the respiratory substrates (10 $\mathrm{mM}$ glutamate $/ 5 \mathrm{mM}$ malate or $5 \mathrm{mM}$ succinate). To induce the respiratory state $3\left(\mathrm{~V}_{3}\right)$ ADP $(125-250 \mathrm{nmol})$ was added. The compounds, when present, were pre-incubated with the mitochondrial suspension, for $2 \mathrm{~min}$, before substrate energization. The respiratory parameters, respiratory control ratio (RCR) and $\mathrm{ADP} / \mathrm{O}$ ratio, were calculated according to Chance and Williams (1956). The uncoupled respiration was measured in the presence of $4 \mu \mathrm{g} / \mathrm{ml}$ oligomycin and $0.5 \mu \mathrm{M}$ FCCP (carbonylcyanide4-trifluoromethoxyphenylhydrazone). The different velocities of mitochondrial respiration, namely $\mathrm{V}_{3}, \mathrm{~V}_{4}$, oligomycin state $\left(\mathrm{V}_{\text {olig }}\right)$ and FCCP state $\left(\mathrm{V}_{\mathrm{FCCP}}\right)$ were determined in order to study the effect of the compounds on mitochondrial bioenergetics, as previously described (Du et al., 1998).

\subsection{Measurements of mitochondrial transmembrane electrical potential $(\Delta \Psi)$}

The determination of $\Delta \Psi$ was made indirectly by the continuous registration of the lipophilic cation tetraphenylphosphonium $\left(\mathrm{TPP}^{+}\right)$transport across the inner mitochondrial membrane using a $\mathrm{TPP}^{+}$-selective electrode prepared in our laboratory, in combination with a $\mathrm{Ag} / \mathrm{AgCl}$-saturated reference electrode (model MI 402, Microelectrodes, Inc. Bedford, NH) (Kamo et al., 1979). Both electrodes were immersed into the same chamber and connected to a pH meter (model 3305; Jenway, Essex, UK). The signals were simultaneously fed to a dual-trace potentiometric recorder (model BD 121; Kipp \& Zonen). Mitochondria (1-1.5 mg) were incubated in $1 \mathrm{ml}$ of the reaction medium containing $125 \mathrm{mM}$ sucrose, $65 \mathrm{mM} \mathrm{KCl}, 2.5 \mathrm{mM} \mathrm{MgCl}_{2}$, $5 \mathrm{mM} \mathrm{KH}_{2} \mathrm{PO}_{4}, 10 \mathrm{mM}$ HEPES ( $\mathrm{pH} 7.2$ ) and $3 \mu \mathrm{M} \mathrm{TPP}$. The reaction mixtures were continuously stirred and the temperature maintained at $30^{\circ} \mathrm{C}$. The respiratory substrates used were $10 \mathrm{mM}$ glutamate $/ 5 \mathrm{mM}$ malate or $5 \mathrm{mM}$ succinate (supplemented or not with $3 \mu \mathrm{M}$ rotenone). The phosphorylation cycle was initiated by the addition of ADP at a convenient concentration (125-250 nmol). When present, the compounds were incubated with the mitochondrial suspension before the addition of the ADP. The $\Delta \Psi$ was determined assuming that the $\mathrm{TPP}^{+}$distribution between the mitochondria and the medium follows the Nernst equation: $\Delta \Psi(\mathrm{mV})=59 \log (v / V)-59 \log \left(10 \Delta^{E / 59}-1\right)$, in which $v, \mathrm{~V}$ and $\Delta E$ are the mitochondrial volume, incubation medium volume and deflection of the electrode potential from the base line, respectively (Kamo et al., 1979). The matrix volume was assumed as $1.1 \mu \mathrm{l} / \mathrm{mg}$ protein Masini et al. (1984). The purpose of our experiments was to show relative changes in potentials, so no correlation was made for the "passive" binding of $\mathrm{TPP}^{+}$to the mitochondrial membranes.

\subsection{Mitochondrial lipid peroxidation}

The evaluation of lipid peroxidation in mitochondria was done using 3 different approaches:

\subsubsection{Oxygen consumption measurements}

The lipid peroxidation was indirectly measured by the oxygen consumption, as previously described (Sassa et al., 1990; Abreu et al., 2000), using an Hansatech electrode. In these experiments mitochondrial suspensions $(1 \mathrm{mg} / \mathrm{ml})$ were incubated in $2.5 \mathrm{ml}$ of peroxidation medium containing $175 \mathrm{mM} \mathrm{KCl}, 10 \mathrm{mM}$ Tris- $\mathrm{HCl}$ ( $\mathrm{pH}$ 7.4), supplemented with $3 \mu \mathrm{M}$ rotenone. The lipid peroxidation was initiated by the simultaneous addition of $1 \mathrm{mM} \mathrm{ADP}$ and $0.1 \mathrm{mM} \mathrm{FeSO}_{4}$. When present, the compounds were incubated 2 min before the induction of lipid peroxidation.

\subsubsection{TBARS assay}

The determination of the amount of thiobarbituric acid reactive substances (TBARS) was performed following the method described by Rohn et al., 1993, with some modifications. The reactions previously described for monitoring oxygen consumption associated with lipid peroxidation, were also used to quantify the amount of TBARS. So, at selected time intervals, aliquots of $450 \mu \mathrm{l}$ were collected from the incubation chamber and mixed with $500 \mu \mathrm{l}$ of ice cold trichloroacetic acid (TCA) $40 \%$, to stop the lipid peroxidative reaction and again mixed with $2 \mathrm{ml}$ of thiobarbituric acid (TBA) $0.67 \%$. The mixture was heated at $100{ }^{\circ} \mathrm{C}$, during $15 \mathrm{~min}$, and re-cooled on ice for $10 \mathrm{~min}$ more. The samples were then centrifuged at $1500 \mathrm{~g}$, for $8 \mathrm{~min}$ (centrifuge Sorvall RT6000). The supernatants were collected and the absorbance was read at $530 \mathrm{~nm}$, against a blank, using a spectrophotometer Bausch \& Lamb, Spectronic 21. The final amount of TBARS was calculated using a molar extinction coefficient of $1.56 \times 10^{5} \mathrm{M}^{-1} \mathrm{~cm}^{-1}$ and expressed as nmol TBARS/mg protein (Buege and Aust, 1978).

\subsubsection{Mitochondrial $\Delta \Psi$ collapse}

The collapse of $\Delta \Psi$ promoted by $\mathrm{ADP} / \mathrm{Fe}^{2+}$ in energized rat liver mitochondria was monitored using the $\mathrm{TPP}^{+}$electrode. In these experiments, mitochondria $(1.5 \mathrm{mg} / \mathrm{ml})$ were incubated at $30^{\circ} \mathrm{C}$, in $1 \mathrm{ml}$ of peroxidation medium containing $175 \mathrm{mM} \mathrm{KCl}, 10 \mathrm{mM}$ Tris- $\mathrm{HCl}$ ( $\mathrm{pH}$ 7.4), supplemented with $3 \mu \mathrm{M}$ TPP, $3 \mu \mathrm{M}$ rotenone and $1.5 \mu \mathrm{M}$ oligomycin. Mitochondria were energized with $5 \mathrm{mM}$ succinate. After mitochondria's incubation with the compounds, for $2 \mathrm{~min}$, the lipid peroxidation was induced by the simultaneous addition of $\mathrm{ADP}(1 \mathrm{mM})$ and $\mathrm{FeSO}_{4}(0.1 \mathrm{mM})$ and $\Delta \Psi$ followed along the time.

\subsection{Cell culture}

In this work, 2 different cells lines, L929 fibroblasts and PC12 cells, were used. The L929 has been considered as a user-friendly model for viability studies (Fischer et al., 2003) and was used just to assess the compounds toxicity. Cells obtained from ECACC were grown in $75 \mathrm{~cm}^{2}$ tissue culture flasks, in DMEM medium supplemented with $10 \%(\mathrm{v} / \mathrm{v})$ heat-inactivated fetal bovine serum (FBS) and $1 \%(\mathrm{v} / \mathrm{v})$ of an antibiotic/antimycotic solution containing 10,000 units of penicillin, $10 \mathrm{mg}$ streptomycin and $25 \mu \mathrm{g}$ amphotericin $\mathrm{B}$ per $\mathrm{ml}$.

The PC12 cell line, established from a rat adrenal pheochromocytoma is a neuronal cell model, usually used to study phenomena related with oxidative stress (Pereira et al., 1999; Silva et al., 2006). The PC12 cells were grown in RPMI-1640, supplemented with $10 \%(\mathrm{v} / \mathrm{v})$ heat-inactivated horse serum, $5 \%(\mathrm{v} / \mathrm{v})$ heat-inactivated FBS and $1 \%(\mathrm{v} / \mathrm{v})$ antibiotic/antimycotic solution (as described above). Before experiments cells, which grow in suspension, were carefully separated by gently pipetting and plated in multi-wells previously coated with poly-D-lysine $(0.1 \mathrm{mg} /$ $\mathrm{ml}$ ) to promote cell adherence.

Both cell lines were kept at $37^{\circ} \mathrm{C}$ in an incubator with a humidified atmosphere and $5 \% \mathrm{CO}_{2}$.

\subsection{Cell viability test}

Cell viability was determined by the MTT reducing test following the method described by Mosmann, 1983. The L929 cells were plated at $5 \times 10^{5}$ cells $/ \mathrm{ml}(0.5 \mathrm{ml} /$ well $)$ and left for adhesion during $5 \mathrm{~h}$. After overnight incubation with the compounds the cells were washed with Krebs medium containing $140 \mathrm{mM} \mathrm{NaCl}, 5 \mathrm{mM} \mathrm{KCl}$, 
$1.5 \mathrm{mM} \mathrm{CaCl}_{2}, 1 \mathrm{mM} \mathrm{NaH}_{2} \mathrm{PO}_{4}, 5.6 \mathrm{mM}$ glucose and $20 \mathrm{mM}$ HEPES, at $\mathrm{pH}$ 7.4. The cells were then incubated with $500 \mu \mathrm{l}$ MTT (final concentration $0.5 \mathrm{mg} / \mathrm{ml}$, in Krebs medium) for $2 \mathrm{~h}$. In order to dissolve the formazan crystals, $0.04 \mathrm{M}$ hydrogen chloride, in isopropanol, was added to each well. The plate was then covered with aluminium foil and put on orbital shaking $2 \mathrm{~h}$ more. After careful dissolution of formazan crystals the absorbance was measured at $570 \mathrm{~nm}$ in a microplate reader Spetra Max 340PC. The percentage of viability was calculated towards a control value obtained in the presence of the compounds solvent, DMSO, alone. A positive control of cells treated with $5 \mathrm{mM} \mathrm{H}_{2} \mathrm{O}_{2}$ was also done.

\subsection{Measurement of cellular TBARS}

The method used for TBARS measurements was previously described (Agostinho et al., 1997; Silva et al., 2006) with some modifications. PC12 cells were plated in poly-D-lysine coated 6well plates at a density of $1.3 \times 10^{6}$ cells $/ \mathrm{ml}$ ( $2 \mathrm{ml}$ for each well) and left for adhesion overnight. The following day, cells were washed with Krebs medium ( $\mathrm{pH} 7$ ) and incubated for 30 min more with the compounds in a final volume of $2 \mathrm{ml}$ of Krebs medium ( $\mathrm{pH}$ 7), supplemented with $100 \mu \mathrm{M}$ EGTA. After this incubation period, the lipid peroxidation was induced by adding the oxidant pair $2 \mathrm{mM}$ ascorbate $/ 0.2 \mathrm{mM} \mathrm{FeSO}_{4}$, for $30 \mathrm{~min}$. The medium was then removed and the reaction stopped by adding, $600 \mu \mathrm{l}$ of ice-cold $15 \mathrm{mM}$ Tris, pH 7.4, per well, to lyse the cells. Disrupted cells were scrapped from each well and the contents of two of them, in the same experimental condition, were pooled. To quantify TBARS formation, $1 \mathrm{ml}$ of each pool was mixed with $2 \mathrm{ml}$ of a solution containing $0.38 \%$ TBA $(\mathrm{w} / \mathrm{v}), 37.5 \%$ TCA $(\mathrm{v} / \mathrm{v})$ and $0.015 \%$ butylated hydroxitoluene (BHT) (w/v), boiled for $15 \mathrm{~min}$, cooled off on ice and centrifuged at $3000 \mathrm{rpm}$ for $10 \mathrm{~min}$. The absorbance of the supernatants was measured at $530 \mathrm{~nm}$ in a Spectra Max 340PC microplate reader.

The TBARS concentration, that is MDA equivalents that react with the TBA reagent (Girotti, 1998), was calculated by using the following equation: $C_{\mathrm{TBARS}}=\left(V \times \mathrm{OD}_{530 \mathrm{~nm}}\right) /(\varepsilon \times \mathrm{mg}($ protein $) \times l)$, where $\mathrm{V}$ represents the dilution factor, $l$ the thickness of the well $(0.753 \mathrm{~cm})$ and $\varepsilon$ the molar extinction coefficient $\left(1.56 \times 10^{5} \mathrm{M}^{-1} \mathrm{~cm}^{-1}\right)$. The amount of protein was estimated in each sample by the Bradford method, with BSA as standard, and the results expressed in terms of nmol TBARS/ mg protein.

\subsection{Determination of radical scavenging capacity-DPPH assay}

The radical scavenging capacity of the compounds was measured by the DPPH (2,2-diphenil-1-picrylhydrazyl) assay described by Silva et al., 2006. This method is based on the evaluation of the capacity of a compound to reduce the DPPH radical.

Samples of different compounds concentrations (10 $\mu \mathrm{l}$ of each, in triplicate) were placed in a 96-well plate and mixed with $180 \mu \mathrm{l}$ of a $0.002 \%$ ethanolic DPPH solution. The absorbance of the mixture was monitored during $60 \mathrm{~min}$, at $517 \mathrm{~nm}$, in a Spectra Max 340PC microplate reader. A Trolox solution and a control with the drug solvent alone (DMSO) were also prepared. The colour of the adequate control was considered as $100 \%$. The $\mathrm{IC}_{50}$ value was determined from the dose response-curve of the percentage of DPPH discoloration.

\subsection{Determination of iron chelation capacity}

The compounds capacity to chelate iron $\left(\mathrm{Fe}^{3+}\right)$ was determined spectrophotometrically, according to the method described by Mira et al., 2002. The absorption spectra of the compound's solution $(100 \mu \mathrm{M})$ were read at both $\mathrm{pH} 7.4$ (in $20 \mathrm{mM}$ HEPES buffer) and $\mathrm{pH} 5.5$ (in $50 \mathrm{mM}$ potassium acetate buffer), at room temper- ature, between 200 and $600 \mathrm{~nm}$, in a spectrophotometer Perkin Elmer Lambda 2 UV/vis. The absorption spectra of the compounds combined with $\mathrm{FeCl}_{3}(100 \mu \mathrm{M})$ were also measured. Both spectra were run against appropriate blanks.

\subsection{Statistical analysis}

The results were expressed as mean \pm SEM of the number of experiments $(\mathrm{n})$ indicated in the legend of each figure. The statistical significance was determined by using a one-way ANOVA, followed by a Newman-Keuls post-hoc test. $P$ values $\leqslant 0.05$ were considered as statistically significant.

\section{Results}

\subsection{Compounds effect on mitochondrial lipid peroxidation}

The antioxidant capacity of MJQ1 and MJQ2 was investigated in non-energized mitochondria submitted to severe oxidative stress induced by the oxidant pair $\mathrm{ADP} / \mathrm{Fe}^{2+}$. The compounds effect on lipid peroxidation was evaluated through mitochondrial oxygen consumption and by the TBARS assay as described elsewhere (Abreu et al., 2000). The compounds capacity of protecting mitochondrial membranes from electrical gradient $(\Delta \Psi)$ collapse, induced by the same oxidant pair, was also evaluated (Figs. 2-4).

\subsection{Oxygen consumption monitorization}

Results on Fig. 2A show that MJQ1 concentrations up to $32 \mathrm{pmol} / \mathrm{mg}$ protein $(32 \mathrm{nM})$, prolonged the initial time (lag-time) of oxygen consumption with increasing drug concentrations, but did not alter the oxygen consumption related with the propagation phase of lipid peroxidation. The MJQ1 concentration of $48 \mathrm{pmol} /$ mg protein $(48 \mathrm{nM})$ totally inhibits the oxygen consumption, so at this concentration the antioxidant activity can be considered as maximal.

In Fig. 2B, MJQ2 concentrations of 25 and $38 \mathrm{nmol} / \mathrm{mg}$ protein (25 and $38 \mu \mathrm{M}$, respectively) prolonged the lag-time but had no effect on posterior oxygen consumption rate. A MJQ2 concentration of $56 \mathrm{nmol} / \mathrm{mg}$ protein $(56 \mu \mathrm{M})$ completely inhibits the oxygen consumption, which means maximal antioxidant activity for a concentration 1000 times greater than the one effective for MJQ1.

\subsection{TBARS production and $I C_{50}$ determination}

In order to confirm the compounds antioxidant activity observed, by oxygen consumption experiments, the malondialdehyde (MDA) production was also followed in the same experimental conditions, for $30 \mathrm{~min}$.

Results in Fig. 3 confirmed the protective effect of both compounds on lipid peroxidation, represented by the decrease in thiobarbituric acid-reactive substances (TBARS) formation, along the time $(30 \mathrm{~min})$. A similar profile of protection was obtained by monitorization of TBARS and oxygen consumption shown in Fig. 2.

Data from Fig. 3 allowed us to calculate the $\mathrm{IC}_{50}$ values, which are the concentration required for $50 \%$ inhibition of TBARS production. We found $\mathrm{IC}_{50} \mathrm{~S}$ of $23.5 \mathrm{nM}$ and $30 \mu \mathrm{M}$ for MJQ1 and MJQ2, respectively. MJQ1 is much more potent in the protection against lipid peroxidation than MJQ2. Comparing these $\mathrm{IC}_{50}$ values with the one obtained for Trolox, in the same experimental conditions ( $18.8 \mu \mathrm{M}$, reported by Abreu et al., 2000) we can say that MJQ1 is clearly more potent than that reference compound.

The compound's concentration range chosen for the subsequent studies is based on the concentration at which each compound inhibited mitochondrial lipid peroxidation. 

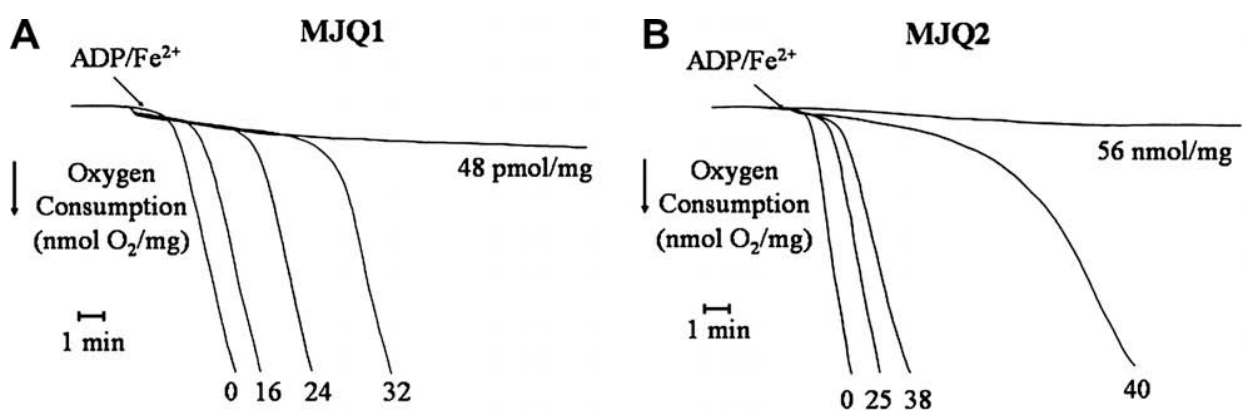

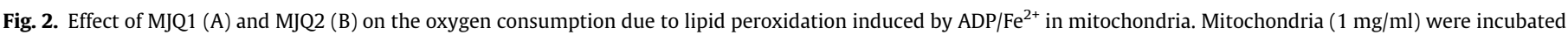

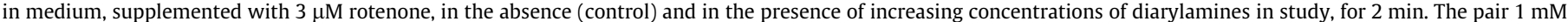

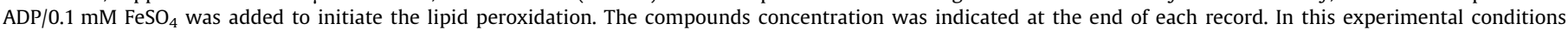

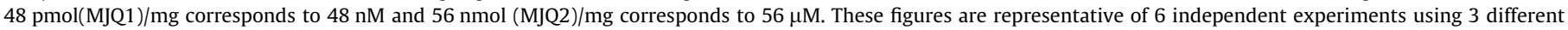
mitochondrial preparations.
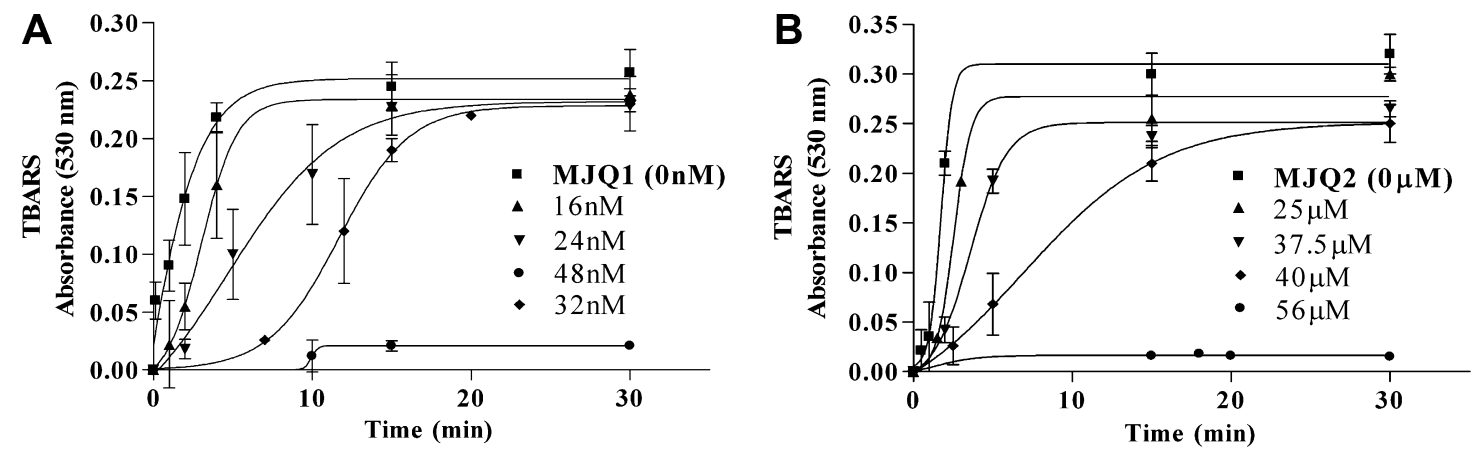

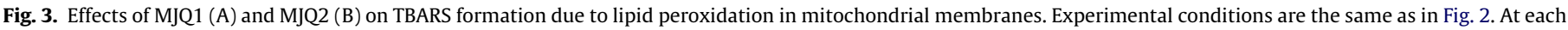

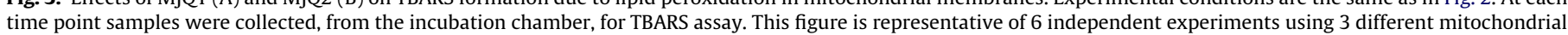
preparations.
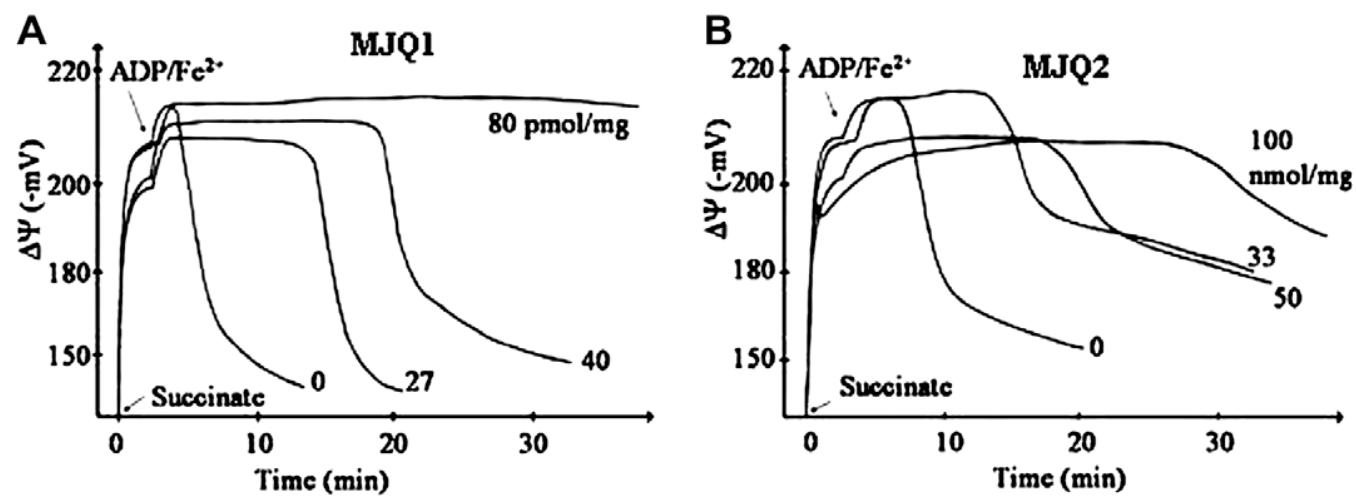

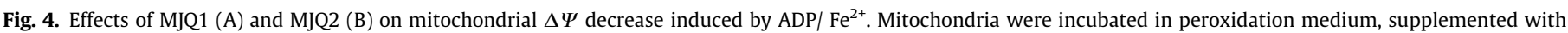

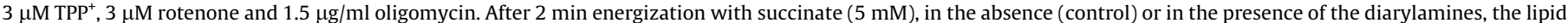

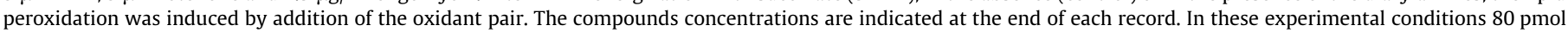

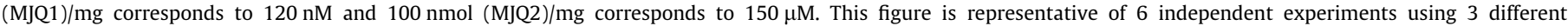
mitochondrial fractions.

\subsection{Effects on mitochondrial $\Delta \Psi$ collapse}

Mitochondrial inner membrane disruption induces a protonmotive force $(\Delta p)$ collapse, in which the electrical gradient $(\Delta \Psi)$ is the main component. Thus, the continuous registration of $\Delta \Psi$ fluctuations, in mitochondria subjected to severe oxidative stress, constitutes an excellent instrument to follow the protective effects of antioxidants (Abreu et al., 2000). Fig. 4 shows effects of MJQ1 and MJQ2, at different concentrations, on the mitochondrial $\Delta \Psi$ fluctuations associated with the respiratory process, in the presence of the oxidant pair $\mathrm{ADP} / \mathrm{Fe}^{2+}$. Mitochondria were energized with succinate in the presence of oligomycin, to prevent the depolarization that occurs in normal conditions, at the moment of ADP addition.

The addition of the oxidant pair $\mathrm{ADP} / \mathrm{Fe}^{2+}$ results in a $\Delta \Psi$ collapse, attributed to membrane disruption induced by lipid peroxidation (Fig. 4) This effect was verified after a lag-phase, which may correspond to the time needed to produce a significant amount of ROS, enough to initiate the lipid peroxidation cascade.

Still in Fig. 4 we can observe that the compounds in study had a protective effect, preventing the $\Delta \Psi$ collapse in oxidative stress conditions, in a dose-dependent manner. During the time period 
considered, $30 \mathrm{~min}$, MJQ1 had a maximal protection at a concentration of $80 \mathrm{pmol} / \mathrm{mg}$ protein $(120 \mathrm{nM})$, whereas MJQ2 is effective for $100 \mathrm{nmol} / \mathrm{mg}$ protein $(150 \mu \mathrm{M})$. It can also be observed that increasing compounds concentrations promote a small decline in maximal $\Delta \Psi$ value, which is more evident in the presence of MJQ2.

\subsection{Effects on respiratory parameters as a measure of compounds toxicity in mitochondria}

From the continuous recording of oxygen consumption, in the presence of different substrates, we obtained the respiratory parameters RCR and ADP/O ratio (Table 1 ). The RCR control values are indicative of the purity and intactness of mitochondria.

The compound MJQ1 slightly affected the RCR index (with succinate as electron donor) only for a concentration of $80 \mathrm{pmol} / \mathrm{mg}$ protein $(120 \mathrm{nM})$, which is substantially higher than the concentration at which it exhibited maximal antioxidant activity (48 pmol/mg protein or $48 \mathrm{nM}$ ). It should be noted that for this concentration the $\mathrm{ADP} / \mathrm{O}$ ratio remained unchanged, indicating that mitochondrial phosphorylative efficiency remains unaltered. On the other hand, the compound MJQ2, at a concentration of $50 \mathrm{nmol} / \mathrm{mg}$ protein, significantly depressed the RCR and ADP/O indexes, when mitochondria were energized with glutamate/malate, as respiratory substrates. This effect on both respiratory parameters suggests an interference of MJQ2 with mitochondrial bioenergetics.

In order to obtain a more precise indication about mitochondrial targets for these compounds, the following respiratory velocities were evaluated: state 3 respiratory velocity $\left(V_{3}\right)$, state 4 respiratory velocity $\left(\mathrm{V}_{4}\right)$, respiratory velocity in the presence of oligomycin $\left(V_{\text {olig }}\right)$ and in the presence of FCCP $\left(V_{\mathrm{FCCP}}\right)$, using glutamate/ malate and succinate as respiratory substrates (Fig. 5), as previously done by Du and collaborators (Du et al., 1998).

So, as can be observed in Fig. 5A and B, the MJQ1 compound did not change any respiratory rates studied, for concentrations up to $80 \mathrm{pmol} / \mathrm{mg}$ protein $(120 \mathrm{nM})$, using glutamate/malate and succinate as respiratory substrates.

For a MJQ2 concentration of $50 \mathrm{nmol} / \mathrm{mg}$ protein $(75 \mu \mathrm{M})$, there seems to be a trend to affect both the state 3 respiratory rate $\left(V_{3}\right)$ and the respiratory rate in the presence of FCCP $\left(V_{\mathrm{FCCP}}\right)$, using glutamate/malate as the respiratory substrate (see Fig. 5C) although not statistically significant, whereas with succinate, $V_{3}$ and $V_{\mathrm{FCCP}}$ did not change at all (see Fig. 5D). According to Du and collaborators a significant and simultaneous decrease of $V_{3}$ and $V_{\text {FCCP }}$ indicates that the compound interacts with some respiratory chain component. Therefore, we suggest that MJQ2 might be able to

Table 1

Effects of MJQ1 and MJQ2 on the respiratory indexes.

\begin{tabular}{|c|c|c|c|c|}
\hline & \multicolumn{2}{|c|}{ Glutamate/Malate } & \multicolumn{2}{|l|}{ Succinate } \\
\hline & RCR & $\mathrm{ADP} / \mathrm{O}$ & RCR & $\mathrm{ADP} / \mathrm{O}$ \\
\hline \multicolumn{5}{|c|}{ MJQ1 (pmol/mg) } \\
\hline 0 & $7.26 \pm 0.37$ & $3.40 \pm 0.04$ & $5.69 \pm 0.36$ & $1.95 \pm 0.05$ \\
\hline 13 & $7.32 \pm 0.26$ & $3.45 \pm 0.10$ & $5.36 \pm 0.44$ & $1.89 \pm 0.07$ \\
\hline 27 & $7.01 \pm 0.28$ & $3.41 \pm 0.01$ & $5.34 \pm 0.50$ & $1.94 \pm 0.05$ \\
\hline 40 & $7.20 \pm 0.47$ & $3.47 \pm 0.14$ & $4.91 \pm 0.27$ & $2.02 \pm 0.04$ \\
\hline 80 & $7.25 \pm 0.81$ & $3.44 \pm 0.16$ & $* 4.23 \pm 0.08$ & $1.94 \pm 0.03$ \\
\hline \multicolumn{5}{|c|}{ MJQ2 (nmol/mg) } \\
\hline 0 & $7.41 \pm 0.54$ & $3.27 \pm 0.04$ & $4.90 \pm 0.28$ & $1.76 \pm 0.04$ \\
\hline 25 & $* 4.81 \pm 0.41$ & $3.17 \pm 0.03$ & $4.62 \pm 0.87$ & $1.73 \pm 0.04$ \\
\hline 50 & $* 3.95 \pm 0.26$ & $* * 3.06 \pm 0.03$ & $* 3.70 \pm 0.31$ & $1.65 \pm 0.07$ \\
\hline
\end{tabular}

Respiratory control ratio (RCR) and ADP/Oxygen ratio where evaluated in rat liver mitochondria energised with glutamate/malate and succinate. The values are means \pm SEM of 3 independent experiments using 3 different mitochondrial fractions $\left({ }^{*} p \leqslant 0.05,{ }^{* *} p \leqslant 0.01\right.$, compared with the control, in the absence of compounds). affect the electron flux at complex I level at concentrations superior to $75 \mu \mathrm{M}$, that is, much higher than the concentration at which MJQ2 shows maximal antioxidant activity $(\sim 50 \mu \mathrm{M})$.

\subsection{Electrical potential $(\Delta \Psi)$ fluctuations related to the respiratory and phoshorylation cycle}

We also investigated the effects of the diarylamines in the mitochondrial $\Delta \Psi$ associated with respiration and with the phosphorylation cycle, as an indication of compounds toxicity to mitochondria.

In the control situation (Fig. 6A and B), mitochondria developed a $\Delta \Psi$ near $-215 \mathrm{mV}$, generated by mitochondrial respiration sustained by the respiratory substrates glutamate/malate and succinate (state 4). The addition of ADP promoted the immediate membrane depolarization, reflected by a $\Delta \Psi$ reduction of about $30 \mathrm{mV}$ (state 3). This depolarization induced by the ADP addition results from the use of $\Delta p$ s energy, by the ATP synthase. The protons flux turning back, through the ATP synthase, gives the energy necessary to ADP phosphorylation. Following this ADP phosphorylation the $\Delta \Psi$ is recovered to the initial level (repolarization phase), after a short period of time, which is dependent on the amount of ADP present.

Data on Fig. 6A also shows that MJQ1 concentrations up to $3.3 \mathrm{nmol} / \mathrm{mg}$ protein $(50 \mu \mathrm{M})$ did not affect the depolarization/ repolarization curves with both respiratory substrates used. It is important to notice that this concentration is higher then the maximal MJQ1 concentration that exhibited mitochondrial antioxidant activity (48 pmol/mg protein, $48 \mathrm{nM}$ ). However, MJQ2 concentrations of 33 and $50 \mathrm{nmol} / \mathrm{mg}$ protein ( 50 and $75 \mu \mathrm{M}$, respectively), promoted a small decrease in potential, related to the respiration and also depressed the phosphorylation cycle kinetic (mitochondria take more time to phosphorylate the ADP present).

The comparative results of both compounds, obtained in mitochondria, allow us to bring out MJQ1 as the promising compound, safer and very powerful against oxidative stress conditions.

\subsection{Effects on cell survival}

The cytotoxicity of the compounds was then evaluated in a whole cell model using the fibroblast L929 cell line and the MTT reduction assay. Results in Fig. 7 show that the two diarylamines did not affect the cell viability for concentrations up to $100 \mu \mathrm{M}$. Even at this high concentration $(100 \mu \mathrm{M}) \mathrm{MJQ1}$ does not affect cell viability. The same concentration of MJQ2 reduces the cell viability to $89.4 \%$. In both cases the concentrations tested are higher than the concentrations at which the compounds proved to have antioxidant properties in mitochondria ( $50 \mathrm{nM}$ MJQ1 and $60 \mu \mathrm{M}$ MJQ2). However, the results indicate some toxicity for MJQ2, which is in agreement with the observed effects on bioenergetic parameters.

The following experiments were focused on the MJQ1 antioxidant potential and on the elucidation of its mechanism of action.

\subsection{Effect on whole cells lipid peroxidation}

The effect of the MJQ1 compound on the protection against cell lipid peroxidation was performed using the PC12 cell line. The pair ascorbate/ $/ \mathrm{Fe}^{2+}$ was used as the oxidant insult, as in other studies with neuronal cell models (Ferreira et al., 1997; Rego et al., 1998).

Fig. 8 shows TBARS quantification in the presence of the oxidant pair alone or in combination with $50 \mathrm{nM}$ of MJQ1. In this last condition, the protection against lipid peroxidation is clearly evident (about 76\%). Thus, MJQ1, besides conferring a considerable protection against mitochondrial lipid peroxidation (Figs. 2 and 3), also confers an evident protection against cellular lipid peroxidation at the same concentration. 
A

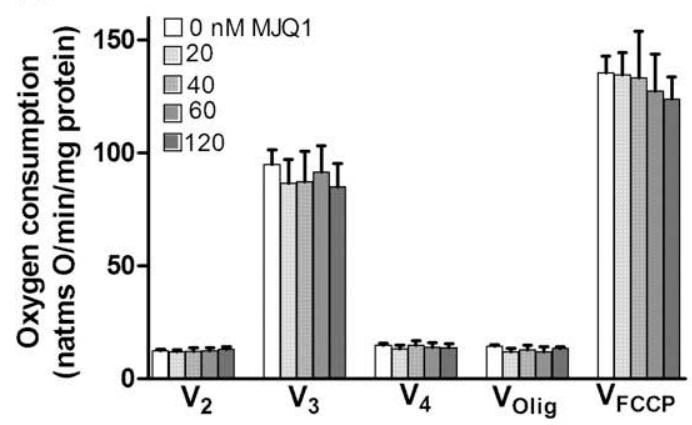

C

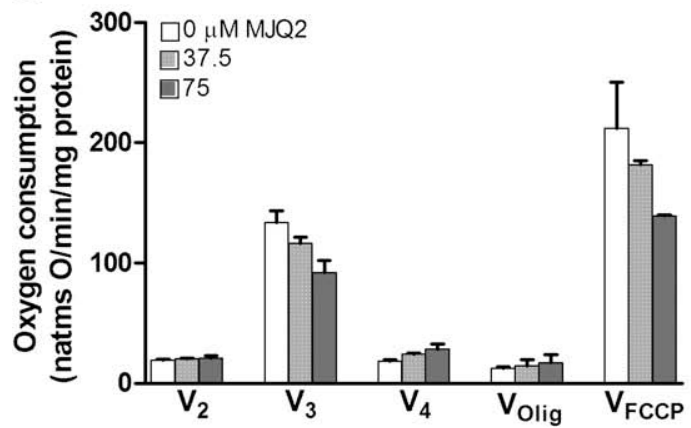

B
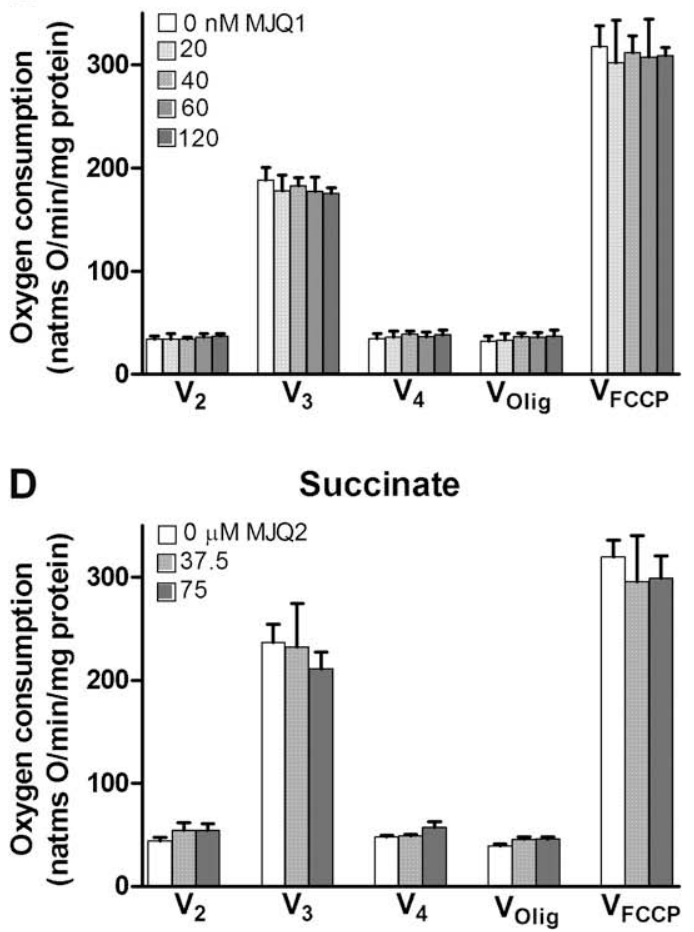

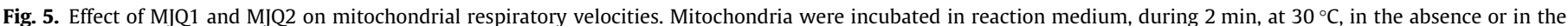

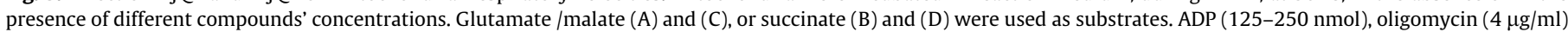
and FCCP $(0.5 \mu \mathrm{M})$ were added as indicated. This figure is representative of 6 independent experiments using 3 different mitochondrial fractions.

A

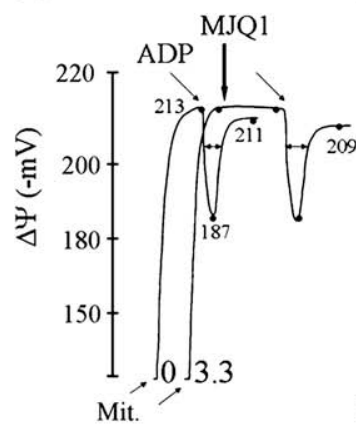

GLUTAMATE/MALATE
MJQ1

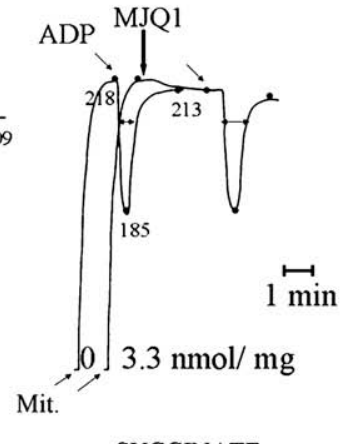

SUCCINATE
B

MJQ2

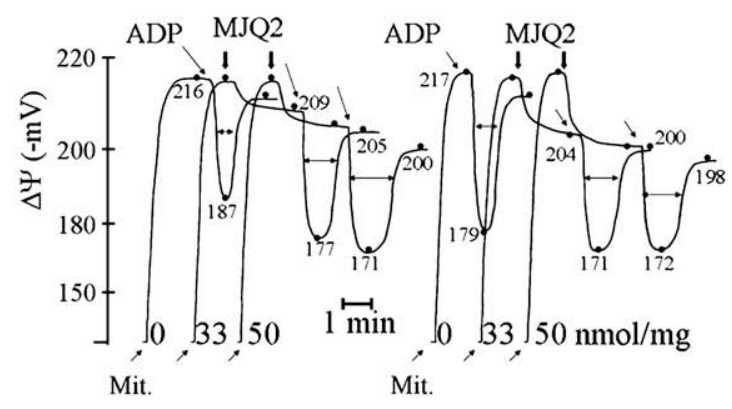

GLUTAMATE/MALATE

SUCCINATE

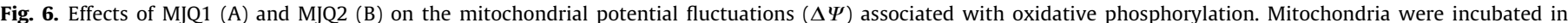

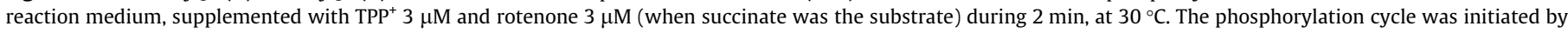

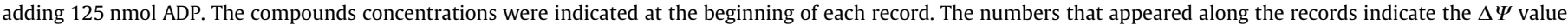
$(-\mathrm{mV})$ measured in each moment. This figure is representative of 6 independent experiments using 3 different mitochondrial fractions.

\subsection{Radical scavenging and iron chelating capacities}

The radical scavenging capacity of MJQ1 was evaluated by the DPPH radical reduction method.

Results on Fig. 9 show an increase in DPPH discoloration as a function of the MJQ1 $(1-100 \mu \mathrm{M})$ and Trolox $(1-20 \mu \mathrm{M})$ concentrations. The $\mathrm{IC}_{50} \mathrm{~S}$ found are indicative of a DPPH radical scavenging activity of MJQ1 similar to the standard antioxidant Trolox.

As the iron chelation ability could account for compounds' antioxidant capacity, in biological systems, we tried to understand if this is the case of MJQ1. So, the formation of the complex "irondyarylamine" was analysed by following the absorption spectra in the presence or absence of $\mathrm{FeCl}_{3}$. Results in Fig. 10 show no dif- ference between the absorption spectra of the compound in the presence and in the absence of iron ions $\left(\mathrm{Fe}^{3+}\right)$, indicating that the antioxidant mechanism of this diarylamine does not seem to be mediated by its iron ions $\left(\mathrm{Fe}^{3+}\right)$ chelating ability.

\section{Discussion}

We tried to characterize the antioxidant activity of new synthetic diarylamines available in our lab, with the objective of finding active principles that could be helpful either in prevention or in treatment of oxidative stress related diseases.

The molecules in study have in common a benzo[ $b]$ thiophene nucleus but also exhibit some structural differences that proved 


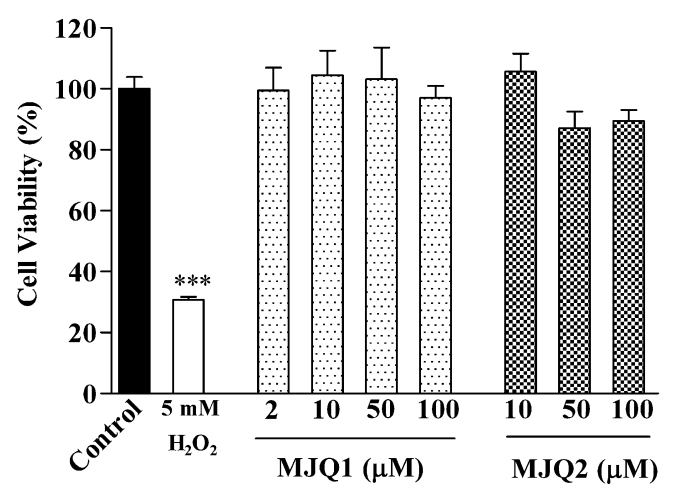

Fig. 7. Cellular viability assessed by the MTT reduction test. L929 cells $\left(5 \times 10^{5}\right.$ cells $/ \mathrm{ml}$ ) were incubated overnight, in the absence and in the presence of increasing concentrations of diarylamines. MTT $(0.5 \mathrm{mg} / \mathrm{ml})$ was added for $2 \mathrm{~h}$ more. The cell viability was calculated as a percentage of the absorbance values read at $570 \mathrm{~nm}$, relative to a control containing the drug solvent DMSO. A positive control with $5 \mathrm{mM} \mathrm{H}_{2} \mathrm{O}_{2}$ was also done. Each column represents the mean values $\pm \mathrm{SEM}$ of 3 independent experiments $\left({ }^{* * *} p \leqslant 0.001\right.$, compared to control).

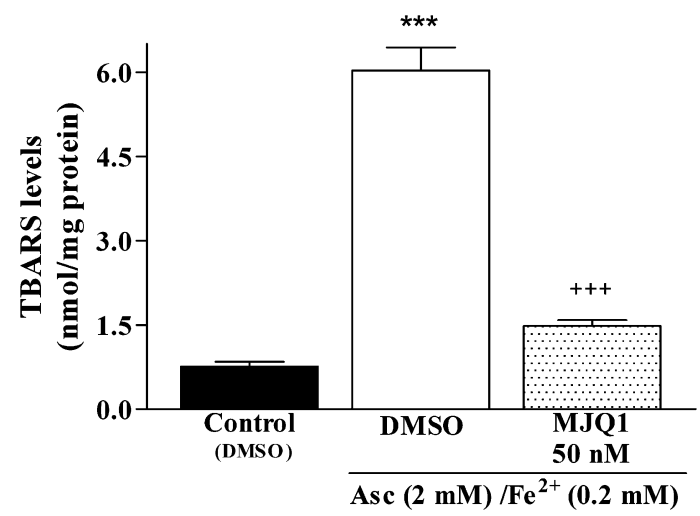

Fig. 8. Effect of MJQ1 on lipid peroxidation induced by $2 \mathrm{mM}$ ascorbate/0.2 $\mathrm{mM}$ $\mathrm{Fe}^{2+}$. PC12 cells were plated at density $2.6 \times 10^{6}$ in Krebs medium ( $\mathrm{pH} \mathrm{7)}$, supplemented with EGTA $(100 \mu \mathrm{M})$. Incubation with the compound $(0.05 \mu \mathrm{M})$ occurred for $30 \mathrm{~min}$. Lipid peroxidation was induced by subsequent addition of the oxidant pair. TBARS levels were calculated using the absorbance values obtained at $530 \mathrm{~nm}$, corrected for the protein concentration in each one. The values are the mean \pm SEM of 3 determinations. $\left({ }^{* * *} p \leqslant 0.001\right.$, compared to control and ${ }^{+++} p \leqslant 0.001$, compared to cells exposed to the oxidant pair).

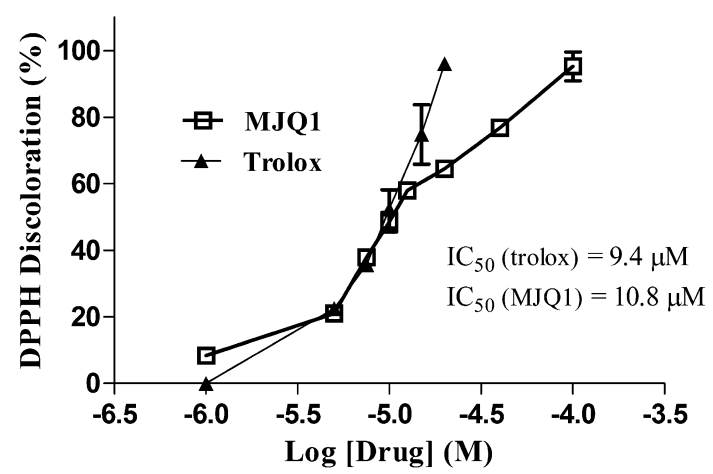

Fig. 9. Dose response curves for DPPH reduction by MJQ1 and Trolox. Different concentrations of MJQ1 and Trolox were added to an ethanolic solution of DPPH. The discoloration of DPPH radical was measured spectrophotometrically, at $517 \mathrm{~nm}$, during $60 \mathrm{~min}$. The values are the mean \pm SEM of 3 independent determinations.

to originate different properties, in which respects to their antioxidant activity in biological models.

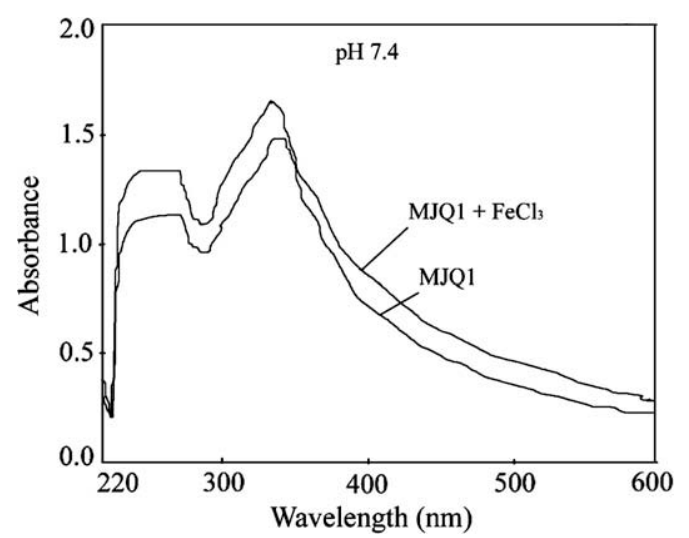

Fig. 10. Absorption spectra of MJQ1 and MJQ2 in the presence and absence of $\mathrm{FeCl}_{3}$. The absorption spectra were measured for $100 \mu \mathrm{M}$ solutions of each compound, in HEPES buffer at $\mathrm{pH}$ 7.4. Each spectrum is representative of, at least, 3 different experiments.

The oxidative damage induced by reactive species in the cellular membranes, is a key event associated with oxidative stress conditions. Mitochondria are particularly susceptible to lipid peroxidation, since they have a high concentration of polyunsaturated fatty acids and also due to the membrane proximity to ROS generated by the electron transport chain (Kowaltowski and Vercesi, 1999). In this study diarylamines' protection of lipid peroxidation was first evaluated in mitochondria through the oxygen consumption monitorization and also through quantification of TBARS.

The pair $\mathrm{ADP} / \mathrm{FeSO}_{4}$, used as the oxidant insult, has particular relevance in mitochondrial lipid peroxidation induction because, in situations of mitochondrial dysfunction, there is an accumulation of ADP, as a result of mitochondrial ATP synthesis inhibition, as well as release of iron from the respiratory complexes. Therefore, in the presence of an excess of oxygen (for example during an ischemia/reperfusion condition) $\mathrm{ADP}$ and $\mathrm{FeSO}_{4}$ could lead to the production of perferryl complex (ADP- $\mathrm{Fe}^{3+}-\mathrm{O}_{2} \cdot^{-}$), that can initiate lipid peroxidation (Kogure et al., 1998).

When lipid peroxidation is monitored through oxygen consumption two stages can be observed: the first one related to the generation and accumulation of this perferryl complex (ADP$\mathrm{Fe}^{3+}-\mathrm{O}_{2}{ }^{-}$), in the proximity of the membrane surface; the second stage is related with radical chain reactions, due to the ROS attack of unsaturated acyl chains inside the lipid bilayer.

Both compounds in study prolonged the lipid peroxidation lagtime (Fig. 2) so, apparently, they both inactivate ROS at/near the membrane surface. This effect is similar to that observed for BHT (butylated hydroxytoluene), a lipophilic antioxidant compound used as food stabilizer (Kogure et al., 1998). The same study also shows that, contrary to BHT, $\alpha$-tocopherol inhibits the propagation phase of radical chain reactions without affecting the lag-time, which indicates a specific action inside the lipid bilayer.

The MJQ1 and MJQ2 concentrations that led to a higher lipid peroxidation protective effect were $48 \mathrm{pmol} / \mathrm{mg}$ protein $(50 \mathrm{nM})$ and $56 \mathrm{nmol} / \mathrm{mg}$ protein $(60 \mu \mathrm{M})$, respectively (Fig. 2). Despite both diarylamines presenting an evident antioxidant activity, MJQ1 acts at much lower concentrations (nanomolar), compared with MJQ2 that acts at micromolar concentrations.

The compounds protection on mitochondrial lipid peroxidation, assessed by the TBARS method, confirms an effective antiperoxidative effect for both compounds (Fig. 3). Again MJQ1 compound is effective for a much lower concentration than MJQ2 and has an $\mathrm{IC}_{50}$ value even better than that obtained for the reference compound Trolox, in the same experimental conditions.

Results in Fig. 4 show that increasing diarylamines' concentrations prevent the $\Delta \Psi$ collapse promoted by $\mathrm{ADP} / \mathrm{FeSO}_{4}$. This result 
shows that, in conditions of high oxidative stress, the new compounds are able to preserve the mitochondria integrity, which is a crucial factor to maintain cell viability.

To evaluate the compounds mitochondrial toxicity we used a classical methodology in which bioenergetics parameters were evaluated (RCR and ADP/O ratio). The compound MJQ1 did not impair the mitochondrial bioenergetics at concentrations that have denoted antioxidant activity (Table 1 ). The slight RCR decrease observed for $80 \mathrm{pmol} / \mathrm{mg}$ protein $(120 \mathrm{nM})$ is not accompanied by an effect on the $\mathrm{ADP} / \mathrm{O}$ ratio, so should not be interpreted as evidence of any toxic effect, as also observed by others (Ferreira and Gil, 1984; Santos et al., 2002). On the other hand, the compound MJQ2 at a concentration of $50 \mathrm{nmol} / \mathrm{mg}$ protein $(75 \mu \mathrm{M})$, affected the RCR parameter, in the presence of both substrates used and also the ADP/O ratio in the presence of glutamate/malate (Table 1). This means an effect on the mitochondrial phosphorylation efficiency, although $75 \mu \mathrm{M}$ is slightly higher than the concentration at which MJQ2 had denoted maximal antioxidant activity $(60 \mu \mathrm{M})$. This was the first indication of the superiority of MJQ1 compared with MJQ2, certainly related with the structure modification introduced in the first one.

The comparative study between respiratory velocities, in the presence and in the absence of the compounds, allows the understanding of the mechanisms of action of these molecules at the respiratory chain components level. The compounds effect, observed on the respiratory velocities $\left(V_{3}, V_{4}, V_{\text {Olig }}\right.$ and $\left.V_{\mathrm{FCCP}}\right)$, again indicates the superiority of MJQ1 compared with MJQ2. The first one did not affect any of the above mentioned velocities, whereas MJQ2 shows a trend to decrease $V_{3}$ and $V_{\mathrm{FCCP}}$, when glutamate/malate is the electron donor. This suggests that high concentrations of MJQ2 (>75 $\mu \mathrm{M})$ may affect particularly the complex I of mitochondria respiratory chain, although this effect deserves to be further explored.

The monitorization of transmembrane potential $(\Delta \Psi)$ fluctuations, associated with mitochondrial respiration and the phosphorylation cycle, is a powerful instrument for toxicity assessment, since the $\Delta \Psi$ represents the main component of the electrochemical gradient.

From Fig. 6A we can say that MJQ1 does not change the fluctuations of $\Delta \Psi$ characteristic of mitochondrial respiration and phosphorylation cycle. In opposition, MJQ2 promotes a little decrease on maximal $\Delta \Psi$ associated to the respiration and a delay in the normal phosphorylation time, in the presence of both electron donors used (Fig. 6B). It has been suggested (Korshunov et al., 1997) that small decreases (10\%) in the mitochondrial $\Delta \Psi$ are responsible for the effective decrease in ROS production. Considering these results, the small $\Delta \Psi$ decrease promoted by MJQ2 may be explained as a MJQ2 protective effect on mitochondrial ROS production, but this effect has to be clarified to rule out a compound's effect on mitochondrial bioenergetics.

The results above mentioned, obtained with isolated mitochondria, were complemented with some studies in whole cells.

We found no toxicity at all for all the MJQ1 concentrations tested (Fig. 7), which confirm the results obtained with mitochondria. MJQ2, in turn, decreased the cell viability in the concentration range of its maximal antioxidant activity in mitochondria $(60 \mu \mathrm{M})$, however with a variance not statistically significant. The results taken together provide evidence for the safer profile of MJQ1 compared to MJQ2.

The protective effects of MJQ1 on lipid peroxidation were also evaluated in a whole cell model. In this case we used the PC12 cell line, in which the oxidative damage has been correlated with that occurring in neurodegenerative diseases (Pereira et al., 1999). Lipid peroxidation was, in this case, induced by the oxidant pair ascorbate/iron, considering the significant amounts they both can reach in brain tissue and also following the methodology used in other studies with neuronal cell models (Cardoso et al., 1998; Rego et al., 1998; Silva et al., 2006).

The results obtained confirm an evident MJQ1 protective effect against lipid peroxidation at the cellular level (Fig. 8) for the same concentration previously shown to have maximal antioxidant activity in the mitochondrial model ( $50 \mathrm{nM})$.

In this respect MJQ1 emerges as a most promising one with beneficial effects in a nanomolar range. On the other hand, protection of PC12 cells against lipid peroxidation indicates that their target is not only the mitochondrial membranes, but also the plasma membrane. Such a protective effect in a neuronal cell model encourages us to further investigate other cellular targets for this compound with implications in neurodegeneration for example, and clearly indicates that the modification introduced in MJQ1 structure resulted in a clear improvement of the biological activity of this diarylamine.

The results obtained with the DPPH discoloration method allowed us to conclude that MJQ1 has a scavenging activity close to the reference standard Trolox, with both $\mathrm{IC}_{50}$ values close to $10 \mu \mathrm{M}$ (Fig. 9). This fact indicates that the transference of $\mathrm{H}^{\bullet}$, by homolytic breakdown of $\mathrm{N}-\mathrm{H}$ bond, could be the antioxidant action mechanism of this compound. The electron-donating effect of methoxyl group (OMe) by mesomeric effect, as well as the inductive effect of methyl group $\left(\mathrm{CH}_{3}\right)$, on the seventh position of the benzo[ $b]$ thiophene, could also contribute to this scavenging effect of MJQ1. MJQ2 has not the ability to scavenge the DPPH radical (results not shown), possibly due to the presence of an ester group on the thiophene ring (which acts as an electron-withdrawer by a mesomeric effect) and to the pyridine ring, poor in electrons.

The antioxidant capacity of any compound besides being related with the hydrogen atom transfer reaction, could also be due to its capacity to quelate metal ions and/or inhibit oxidative enzymes. Some investigators have proposed the participation of perferryl complex (ADP-Fe ${ }^{3+}-\mathrm{O}_{2}{ }^{-}$) in the initiation and propagation of lipid peroxidation, which also require the presence of oxygen and free iron (Kogure et al., 1998). So, the presence of molecules with the ability to chelate metal ions could reduce the reactive species and, consequently, protect lipid membranes against peroxidation. It has been already demonstrated that desferrioxamine, an iron $\left(\mathrm{Fe}^{3+}\right)$ chelator, limits the amount of free radical production in several different cells and species (Mira et al., 2002; Pardo et al., 2005).

Our results (Fig. 10) showed that there are no changes in the spectra, obtained in the presence or absence of $\mathrm{FeCl}_{3}$, which mean that the antioxidant activity verified for MJQ1 does not seem to be due to their iron chelator properties. Considering that low pH values can be generated during the iron release by oxidized proteins, or in generic processes like phagocytosis, inflammation or during the ischemia/reperfusion injury (Mira et al., 2002), we also looked for spectra alterations at $\mathrm{pH} 5.5$, but again no difference was observed (results not shown).

In conclusion, the new diarylamines show antioxidant activity for non-toxic concentrations, protecting the mitochondrial and cell membranes against lipid peroxidation induced by appropriate deleterious agents.

The structural modification introduced in the chemical structure that resulted in the MJQ1 compound, clearly improved both its antioxidant and toxicity profile. More research is needed to elucidate other intracellular targets and better understand the mechanisms of action of these new molecules. Nevertheless, the results herein presented are of great importance because they open new perspectives for the development of MJQ1 and related compounds as active principles of drugs eventually useful in conditions where oxidative stress is involved. 


\section{Acknowledgments}

PC12 cell line was gently provided by Prof. Catarina Oliveira from CNC, University of Coimbra, Portugal. This work was partially supported by the FCT Project PTDC/QUI/68382/2006. João P. Silva is supported by the FCT Grant SFRH/BH/17174/2004.

\section{References}

Abreu, R.M., Santos, D.J., Moreno, A.J., 2000. Effects of carvedilol and its analog BM910228 on mitochondrial function and oxidative stress. J. Pharmacol. Exp. Ther. 295, 1022-1030.

Agostinho, P., Duarte, C.B., Carvalho, A.P., Oliveira, C.R., 1997. Oxidative stress affects the selective ion permeability of voltage-sensitive Ca2+ channels in cultured retinal cells. Neurosci. Res. 27, 323-334.

Behl, C., 1999. Alzheimer's disease and oxidative stress: implications for novel therapeutic approaches. Prog. Neurobiol. 57, 301-323.

Benedi, J., Arroyo, R., Romero, C., Martin-Aragon, S., Villar, A.M., 2004. Antioxidant properties and protective effects of a standardized extract of Hypericum perforatum on hydrogen peroxide-induced oxidative damage in PC12 cells. Life Sci. $75,1263-1276$

Bouchier-Hayes, L., Lartigue, L., Newmeyer, D.D., 2005. Mitochondria: pharmacological manipulation of cell death. J. Clin. Invest. 115, 2640-2647.

Buege, J.A., Aust, S.D., 1978. Microsomal lipid peroxidation. Methods Enzymol. 52, 302-310.

Cardoso, S.M., Pereira, C., Oliveira, C.R., 1998. The protective effect of vitamin E, idebenone and reduced glutathione on free radical mediated injury in rat brain synaptosomes. Biochem. Biophys. Res. Comm. 246, 703-710.

Chance, B., Williams, G.R., 1956. The respiratory chain and oxidative phosphorylation. Adv. Enzymol. Relat. Areas Mol. Biol. 17, 65-134.

Du, G., Mouithys-Mickalad, A., Sluse, F.E., 1998. Generation of superoxide anion by mitochondria and impairment of their functions during anoxia and reoxygenation in vitro. Free Radic. Biol. Med. 25, 1066-1074.

Esteves, M.A., Narender, N., Marcelo-Curto, M.J., Gigante, B., 2001. Synthetic derivatives of abietic acid with radical scavenging activity. J. Nat. Prod. 64, 761-766.

Ferreira, F.M., Madeira, V.M., Moreno, A.J., 1997. Interactions of 2,2-bis( $p$ chlorophenyl)-1,1-dichloroethylene with mitochondrial oxidative phosphorylation. Biochem. Pharmacol. 53, 299-308.

Ferreira, I.C., Queiroz, M.J., Vilas-Boas, M., Estevinho, L.M., Begouin, A., Kirsch, G. 2006. Evaluation of the antioxidant properties of diarylamines in the benzo[b]thiophene series by free radical scavenging activity and reducing power. Bioorg. Med. Chem. Lett. 16, 1384-1387.

Ferreira, J., Gil, L., 1984. Nutritional effects on mitochondrial bioenergetics alterations in oxidative-phosphorylation by rat-liver mitochondria. Biochem. J. 218, 61-67.

Fischer, D., Li, Y., Ahlemeyer, B., Krieglstein, J., Kissel, T., 2003. In vitro cytotoxicity testing of polycations: influence of polymer structure on cell viability and hemolysis. Biomaterials 24, 1121-1131.

Girotti, A.W., 1998. Lipid hydroperoxide generation, turnover, and effector action in biological systems. J. Lipid Res. 39, 1529-1542.

Gornall, A.G., Bardawill, C.J., David, M.M., 1949. Determination of serum proteins by means of the biuret reaction. J. Biol. Chem. 177, 751-766.

Gulcin, I., Mshvildadze, V., Gepdiremen, A., Elias, R., 2006. The antioxidant activity of a triterpenoid glycoside isolated from the berries of Hedera colchica: 3-O(beta-D-glucopyranosyl)-hederagenin. Phytother. Res. 20, 130-134.

Jang, J.H., Surh, Y.J., 2001. Protective effects of resveratrol on hydrogen peroxide-induced apoptosis in rat pheochromocytoma (PC12) cells. Mutat. Res. 496, 181-190.

Jezek, P., Hlavata, L., 2005. Mitochondria in homeostasis of reactive oxygen species in cell, tissues, and organism. Int. J. Biochem. Cell Biol. 37, 2478-2503.
Kamo, N., Muratsugu, M., Hongoh, R., Kobatake, Y., 1979. Membrane potential of mitochondria measured with an electrode sensitive to tetraphenyl phosphonium and relationship between proton electrochemical potential and phosphorylation potential in steady state. J. Membr. Biol. 49, 105121.

Kogure, K., Sassa, H., Abe, K., Kitahara, K., Sano, Y., Kawano, H., Nakagawa, Y., Terada, H., 1998. Inhibitory effects of pentamethine trinuclear cyanine dyes on ADP/ $\mathrm{Fe}^{2+}$-induced lipid peroxidation in rat liver mitochondria: changes in the mode of action with the hydrophobic nature of the dyes. Biol. Pharm. Bull. 21, 180183.

Korshunov, S.S., Skulachev, V.P., Starkov, A.A., 1997. High protonic potential actuates a mechanism of production of reactive oxygen species in mitochondria. FEBS Lett. 416, 15-18.

Kowaltowski, A.J., Vercesi, A.E., 1999. Mitochondrial damage induced by conditions of oxidative stress. Free Radic. Biol. Med. 26, 463-471.

Lovell, M.A., Ehmann, W.D., Butler, S.M., Markesbery, W.R., 1995. Elevated thiobarbituric acid-reactive substances and antioxidant enzyme activity in the brain in Alzheimer's disease. Neurology 45, 1594-1601.

Masini, A., Ceccarelli-Stanzani, D., Muscatello, U., 1984. An investigation on the effect of oligomycin on state-4 respiration in isolated rat-liver mitochondria. Biochim. Biophys. Acta 767, 130-137.

Mira, L., Fernandez, M.T., Santos, M., Rocha, R., Florencio, M.H., Jennings, K.R., 2002 Interactions of flavonoids with iron and copper ions: a mechanism for their antioxidant activity. Free Radic. Res. 36, 1199-1208.

Mosmann, T., 1983. Rapid colorimetric assay for cellular growth and survival: application to proliferation and cytotoxicity assays. J. Immunol. Methods 65 55-63.

Pardo, A.G., Delgado, R., Velho, J., Inada, N.M., Curti, C., Vercesi, A.E., 2005. Mangifera indica L. extract (Vimang) inhibits $\mathrm{Fe}^{2+}$-citrate-induced lipoperoxidation in isolated rat liver mitochondria. Pharmacol. Res. 51, 427-435.

Pereira, C., Santos, M.S., Oliveira, C., 1999. Involvement of oxidative stress on the impairment of energy metabolism induced by A-beta peptides on PC12 cells: protection by antioxidants. Neurobiol. Dis. 6, 209-219.

Queiroz, M.-J.R.P., Begouin, A., Ferreira, I.C.F.R., Kirsch, G., Calhelha, R.C., Barbosa, S., Estevinho, L.M., 2004. Palladium-catalysed amination of electron-deficient or relatively electron-rich benzo[b]thienyl bromides - preliminary studies of antimicrobial activity and SAR. Eur. J. Org. Chem., 3679-3685.

Rego, A.C., Santos, M.S., Proença, M.T., Oliveira, C.R., 1998. Influence of vitamin E succinate on retinal cell survival. Toxicology 128, 113-124.

Rohn, T.T., Hinds, T.R., Vincenzi, F.F., 1993. Ion transport ATPases as targets for free radical damage. Protection by an aminosteroid of the $\mathrm{Ca}^{2+}$ pump ATPase and $\mathrm{Na}^{+} / \mathrm{K}^{+}$pump ATPase of human red blood cell membranes. Biochem. Pharmacol. 46, 525-534.

Santos, D.L., Moreno, A.J., Leino, R.L., Froberg, M.K., Wallace, K.B., 2002. Carvedilol protects against doxorubicin-induced mitochondrial cardiomyopathy. Toxicol. Appl. Pharmacol. 185, 218-227.

Sassa, H., Takaishi, Y., Terada, H., 1990. The triterpene celastrol as a very potent inhibitor of lipid peroxidation in mitochondria. Biochem. Biophys. Res. Commun. 172, 890-897.

Schinella, G.R., Tournier, H.A., Prieto, J.M., Mordujovich de, B.P., Rios, J.L., 2002 Antioxidant activity of anti-inflammatory plant extracts. Life Sci. 70, 10231033.

Schroeter, H., Williams, R.J., Matin, R., Iversen, L., Rice-Evans, C.A., 2000. Phenolic antioxidants attenuate neuronal cell death following uptake of oxidized lowdensity lipoprotein. Free Radic. Biol. Med. 29, 1222-1233.

Scott, G., 1988. Antioxidants. Bull. Chem. Soc. Jpn. 1, 165-170.

Silva, J.P., Areias, F.M., Proença, F.M., Coutinho, O.P., 2006. Oxidative stress protection by newly synthesized nitrogen compounds with pharmacological potential. Life Sci. 78, 1256-1267.

Valko, M., Rhodes, C.J., Moncol, J., Izakovic, M., Mazur, M., 2006. Free radicals, metals and antioxidants in oxidative stress-induced cancer. Chem. Biol. Interact. 160 $1-40$. 